\title{
Projeto político pedagógico e diretrizes curriculares nacionais da licenciatura em pedagogia
}

Sayuri Miranda de Andrade Kuratani* Universidade Federal da Bahia

Renata Meira Veras** Universidade Federal da Bahia

Resumo $\mathrm{O}$ artigo aborda o tema da formação em Licenciatura em Pedagogia, vinculando-se à discussão das Diretrizes Curriculares Nacionais dessa graduação. Utilizando-se da análise documental, o artigo buscou discutir as relações existentes entre um Projeto Político Pedagógico (PPP) de uma Licenciatura em Pedagogia e essas Diretrizes, apontando questões pertinentes à pauta da formação de professores. A perspectiva metodológica adotada foi a análise foucaultiana do discurso, que valoriza a linguagem e as suas implicações nas práticas sociais. A análise indicou, no PPP, a presença de um discurso prescritivo, de caráter normativo, em consonância às Diretrizes, mas também demonstrou um discurso preocupado em atingir o compromisso e a transformação social. A formação organiza-se em dois eixos principais, que são a pesquisa e a práxis pedagógica, o que enfatiza a identidade de um professor-pesquisador. No PPP, os alunos, docentes e a comunidade são posicionados por uma estrutura de deveres e passividade. Ressaltou-se a importância da constante atualização e problematização da formação nas Licenciaturas, referentes tanto aos Projetos Políticos Pedagógicos, quanto às Diretrizes Curriculares Nacionais.

PALAVRAS-Chave: Pedagogia; Formação de professores; Currículo; Análise foucaultiana do discurso. 


\title{
Political pedagogical project and national curricular guidelines of the degree in pedagogy
}

\begin{abstract}
The article addresses the topic of training for a degree in education, as linked to the discussion surrounding the National Curricular Guidelines. Using documentary analysis, the article sought to discuss existing relations between a Pedagogical Political Project (PPP) related to a degree in education and these Guidelines, pointing out issues pertinent to the teacher training agenda. The methodological perspective adopted was the foucauldian analysis of discourse, which values language and its implications in social practices. In relation to the PPP, the analysis pointed to the presence of a prescriptive discourse, of a normative character, in consonance with the Guidelines, but also identified discourse concerned with attaining commitment and social transformation. The training is organized around two central points - research and pedagogical praxis - which emphasize the identity of a teacher-researcher. In PPP, students, teachers, and the community are positioned by a structure of duties and passivity. The importance of constantly updating and problematizing training in the degree programs was emphasized, referring to both the Political Pedagogical Projects and the National Curricular Guidelines.
\end{abstract}

KEYWORDS: Pedagogy; Teacher education; Curriculum; Foucauldian discourse analysis.

\section{Introdução}

A formação em Pedagogia constitui-se como um campo de estudo relevante nas discussões sobre a formação de professores e sobre as Licenciaturas. Nesse cenário, a compreensão e reflexão dos instrumentos que normatizam essa formação tornam-se objeto de preocupação e análise das coordenações de gestão educacional, universidades e escolas, já que esses dispositivos orientam currículos e revelam intencionalidades formativas que regularão o processo educativo do licenciando e, consequentemente, dos alunos e da escola.

Dentre esses instrumentos, destacam-se, neste artigo, a reflexão sobre as Diretrizes Curriculares Nacionais de Pedagogia (DCNP) (BRASIL, 2006) e a análise do Projeto Político Pedagógico (PPP) de Licenciatura em Pedagogia de uma universidade pública do interior da Bahia. Através de uma análise documental, utilizando o método de análise foucaultiana do discurso, este estudo traz apontamentos sobre os discursos contidos nesse PPP e suas relações com as DCNP.

Para isso, o artigo está estruturado em quatro momentos: o primeiro destaca a construção e a proposta das DCNP; o segundo descreve o método utilizado para análise do documento; o terceiro traz a análise do discurso feita entre as DCNP e o PPP, a partir do que é proposto por Willig (2010); por último, são feitas algumas considerações e reflexões tomando os momentos anteriores. 


\section{A construção das diretrizes curriculares nacionais de peda- gogia}

A definição do papel do pedagogo tem sido amplamente debatida nas últimas décadas e são diversas as identidades atribuídas à Pedagogia e às suas áreas de atuação (AGUIAR et al., 2006). No âmbito das políticas de educação e normatizações para o curso de Pedagogia, conflitos relacionados a esses diferentes sentidos e identidades criaram uma arena tensionada por atores sociais (AGUIAR et al., 2006) que adotam perspectivas e intencionalidades distintas para a construção das Diretrizes Curriculares.

Anterior à formulação dessas diretrizes, a formação nas Licenciaturas ocorria através do "esquema 3+1", no qual o licenciando, após cursar três anos de conteúdos específicos da área, integralizava um ano de disciplinas relacionadas à prática pedagógica. No curso de Pedagogia, o último ano era dedicado ao estudo da didática, dissociando-se dos conteúdos da Pedagogia e ocasionando uma ruptura entre os conhecimentos específicos e os métodos de os ensinar. Ressalta-se que esse modelo foi predominante, mas houve uma flexibilização a partir do Decreto-lei no. 9092, de 1946, que designou que a formação deveria ocorrer em quatro anos para licenciado ou bacharel, compondo três anos de um currículo fixo e um ano de componentes optativos, que poderiam ser definidos a partir da escolha pela licenciatura ou pelo bacharelado. Porém, esse modelo foi facultativo aos centros de ensino (BRZEZINSKI, 2011).

O “esquema 3+1" foi extinto com o Parecer 251/1962 do Conselho Federal de Educação (CFE), estabelecendo o currículo mínimo como proposta formativa do pedagogo, que, além de técnico em educação, tornava-se professor das disciplinas pedagógicas da escola normal (DURLI, 2007).

O currículo mínimo de Pedagogia tinha duração de quatro anos, três deles referentes a uma base comum de conteúdos e um ano era dedicado aos conteúdos de didática e a práticas de ensino, com mais duas disciplinas optativas a serem escolhidas entre doze a serem ofertadas. Para Scheibe e Durli (2011, p. 90), apesar da proposta de concomitância dos conteúdos, permaneceu o modelo do "esquema 3+1": "o bacharelado preparando o técnico em educação e a licenciatura formando o professor para o magistério no ensino secundário e normal".

A partir da Reforma universitária de 1968, houve algumas mudanças estruturais do CFE para o curso de Pedagogia que instalaram as habilitações para formação de especialistas (BRZEZINSKI, 2007). Segundo Scheibe e Durli (2011), o curso de Pedagogia mantinha cinco habilitações básicas: magistério no ensino normal, orientação educacional, administração escolar, supervisão de ensino e inspeção escolar. O currículo mínimo manteve-se, existindo a base comum e a base específica para a formação nas habilitações.

O contexto da Reforma de 68 foi marcado por um projeto de nação tecnocrático, subordinado ao mercado de trabalho e aos planos de desenvolvimento de um governo militar. Este organizou o processo educativo para uma racionalidade técnica, objetivando a produtividade e eficiência, atrelada às exigências do capital, formulando 
uma concepção produtivista de educação (SAVIANI, 2004). Desse modo, as habilitações formavam especialistas na área que, de forma técnica e objetiva, deveriam gerar produtividade e ordenamento nos ambientes educacionais.

Brzezinski (2007, p. 238) explica que a lógica tecnicista que regeu a estrutura pedagógica e curricular gerou excessiva fragmentação da graduação em Pedagogia: “os pedagogos 'especialistas' coordenavam frações do 'organismo escolar' sem a devida articulação entre o pensar e o fazer". O pedagogo encontrava-se fragmentado entre o papel do professor e o do especialista.

A fragmentação, a desconexão entre as propostas formativas e curriculares (SILVA, 1999; SCHEIBE; AGUIAR, 1999) e conflitos na organização do trabalho docente marcaram o curso de Pedagogia durante três décadas, até a aprovação da Lei de Diretrizes e Bases (LDB) em 1996 - Lei no 9.394 (BRASIL, 1996). Durante e após esse período, os conflitos e intenções contrárias entre os movimentos e entidades da educação e o governo se intensificaram, criando um tensionamento entre poder instituinte e instituído (BRZEZINSKI, 2007).

Brzezinski (2007) argumenta sobre as várias investidas do campo do instituído contra a formação de professores no curso de Pedagogia como, por exemplo, o Decreto no 3276/1999 (BRASIL, 1999), no qual foi determinada, arbitrariamente, a retirada da possibilidade de o curso de Pedagogia formar professores de educação infantil e dos anos iniciais do ensino fundamental, tornando-se exclusividade do Curso Normal Superior (no documento lê-se o termo "exclusivamente"). O Movimento Nacional de Educadores resistiu e organizou um espaço instituinte: o Fórum em Defesa da Formação do Professor. Então, no ano 2000, o Decreto no 3554/2000 deu nova redação, trocando o termo "exclusivamente" por "preferencialmente" (BRASIL, 2000). Nesse período, no ano de 1999, a Comissão de Especialistas de Ensino de Pedagogia (CEEP), que atuava como representante da comunidade acadêmica na Secretaria de Educação Superior, elaborou de forma coletiva uma proposta de Diretrizes Curriculares Nacionais (DCN) para a graduação em Pedagogia, já que o Conselho Nacional de Educação (CNE) ainda não tinha uma proposição de Diretrizes (BRZEZINSKI, 2007).

$\mathrm{Na}$ conjuntura da LDB de 1996, caracterizada por um ideário neoliberal e pela racionalidade técnica, a formação em Pedagogia caminhava para um bacharelado de caráter profissionalizante, ligado às especializações de administração e coordenação pedagógica. Esse posicionamento mantinha-se contrário ao que os movimentos e entidades de educação vinham defendendo: a formação para docência como basilar do curso em Pedagogia (SCHEIBE; DURLI, 2011).

Assim, para a construção das DCNP existiam duas propostas em disputa: uma sistematizada pela Comissão de Especialistas de Ensino em Pedagogia (CEEP), com importantes contribuições do Movimento pela Reformulação dos Cursos de Formação dos Educadores, construída conjuntamente com entidades e movimentos sociais na área da educação, apresentada ao Ministério da Educação em 1999; e outra, defendida pelo CNE, voltada para o projeto de formação de professores já em anda- 
mento pelas políticas governamentais e pela $\mathrm{LDB} / 1996$, apresentada à sociedade pela Resolução de 17 de março de 2005 (DURLI, 2007).

Para os educadores que defendiam a proposta de entidades como a Associação Nacional pela Formação dos Profissionais da Educação (ANFOPE), a docência deveria estar embasada por todos os aspectos da ciência pedagógica, visando uma formação ampliada, de compreensão aprofundada da docência e do professor-pedagogo. Conclui-se que esse

[...] é bacharel e licenciado ao mesmo tempo, formado para atuar no magistério, na gestão educacional e na produção e difusão do conhecimento da área da Educação. Engloba, portanto, de modo integrado, as funções de professor, de gestor e de pesquisador. (SCHEIBE; DURLI, 2011, p. 103).

A proposta defendida pelo CNE conservava uma concepção restrita de docência, mantendo uma formatação semelhante ao que era previsto para o Curso Normal Superior. Baseado-se nisso, no ano de 2005, a Comissão Bicameral do CNE apresentou uma proposta inicial de DCN e, sob forte mobilização social, com intensas discussões e manifestações, o CNE reelaborou-a, aproximando-se das proposições defendidas pela Comissão de Especialistas de Ensino em Pedagogia (CEEP) e representações sociais da educação, que defendiam a ampliação do conceito de docência (DURLI, 2007).

As DCN tornaram-se instituídas com os Pareceres CNE/CP no 05/2005, no 03/2006 e com a Resolução CNE/CP no 01, de 15 de maio de 2006. Na Enciclopédia de Pedagogia Universitária, encontramos uma definição das DCNP, que:

[...] são entendidas como um conjunto de princípios, fundamentos e procedimentos a serem observados na organização institucional e curricular. Expressam a finalidade, os objetivos, o perfil do pedagogo (licenciado), a organização curricular e a duração dos estudos do curso de Pedagogia. Aplica-se à formação inicial para o exercício da docência na Educação Infantil e nos Ános Iniciais do Ensino Fundamental, nos cursos de Ensino Médio, na modalidade Normal, em cursos de Educação Profissional na área de serviços e apoio escolar, bem como em outras áreas nas quais sejam previstos conhecimentos pedagógicos. (BRZEZINSKI, 2006, p. 192-193).

As DCN sinalizaram que a formação do pedagogo deverá articular a docência, a gestão educacional e a produção de conhecimento (AGUIAR et al., 2006), reafirmando a proposta da CEEP, ANFOPE e outras entidades quanto à formação do pedagogo pela licenciatura e pelo bacharelado, na tentativa de superar a dicotomia histórica entre o professor-técnico e a docência-pesquisa, e de impedir a fragmentação curricular pelas habilitações, que foram extintas.

No artigo 2 das DCNP (BRASIL, 2006), é definido seu objetivo, referindo-se ao exercício da docência na educação infantil, nos anos iniciais do ensino fundamental, nos cursos de ensino médio, na modalidade normal, em cursos de educação profissional na área de serviços e apoio escolar, e em outras áreas relacionadas com conhecimentos pedagógicos. Descreve-se no parágrafo $1^{\circ}$ uma compreensão ampliada 
de docência, ressaltando os aspectos sociais, culturais, econômicos e científicos inerentes a essa prática. Para Durli (2007, p. 192), há uma tentativa de aproximação da compreensão de docência defendida pelos movimentos, contudo a concepção ainda se mostra ambígua, principalmente por se referir à docência como base do licenciado, mas não do pedagogo em geral, como previsto pela ANFOPE, pois tomar "[...] o princípio da docência como base, tem seu valor vinculado à possibilidade de formar o pedagogo enquanto educador generalista, licenciado e bacharel ao mesmo tempo".

A docência evidencia-se enquanto pilar nas DCN, contudo Aguiar e colaboradores (2006) alertam que, ao definir o curso de Pedagogia como Licenciatura, não se pode cometer o equívoco de restringir a matriz curricular a metodologias de ensino ou a conteúdos específicos à docência da educação infantil, anos iniciais do ensino fundamental, ensino médio ou profissional, pois “[...] o exercício da docência desenvolve-se no contexto mais amplo da educação, da escola e da própria sociedade [...]" (AGUIAR et al., 2006, p. 832).

As DCNP resultaram de embates políticos e epistemológicos que geraram determinadas consonâncias, porém também paradoxos, como descreve Saviani (2007). Para a superação destes, os cursos de Pedagogia demandam a criação de novas formas de pensar-fazer essa formação.

\section{O documento em análise}

O presente artigo traz uma análise documental do Projeto Político Pedagógico de um curso noturno de Licenciatura em Pedagogia (que será denominado de PPP - LP para as citações neste artigo), de uma universidade pública do interior da Bahia, partindo da compreensão das DCNP e suas implicações e atuações para o campo formativo. Baseado nas discussões do Colegiado e na reorientação curricular do curso diurno de Licenciatura em Pedagogia, implantado anteriormente na mesma universidade, esse PPP, construído nos anos de 2007-2008, retrata a criação do curso noturno e revela sua preocupação com a constituição da identidade do pedagogo no interior da Bahia e seu impacto social na formação de professores nessa região e na democratização do acesso à universidade pública, oportunizando o ingresso do aluno trabalhador (PPP - LP).

A construção de um PPP é um desafio para a universidade brasileira e a construção deste requer a análise das complexidades econômicas, políticas e culturais das realidades a que os cursos estão implicados (CABRAL NETO, 2004), definindo precisamente sua opção política no projeto (FERREIRA, 2004).

Para o Fórum de Pró-Reitores de Graduação das Universidades Brasileiras (ForGRAD) o PPP pode ser compreendido

[...] como um instrumento de balizamento para o fazer universitário, concebido coletivamente no âmbito da instituição, orientado para esta, como um todo, e para cada um de seus cursos, em particular. Ao constituir-se, o Projeto (político) Pedagógico deve ensejar a construção da intencionalidade para o desempenho do papel social da IES, centrando-se no ensino, mas vinculando-se estreitamente aos processos de pesquisa e extensão. (ForGRAD, 1999, p. 7). 
A elaboração do PPP deve ser uma ação coordenada pelos colegiados de cursos, com o envolvimento coletivo de professores, alunos, especialistas na área e representantes da sociedade (CABRAL NETO, 2004), expressando as diretrizes políticas, pedagógicas e técnicas de um curso de graduação, requerendo contínua avaliação e aperfeiçoamento da proposta político-pedagógica definida (SILVA, 2004).

\section{Método}

Para a análise desse documento foi utilizado o método de análise foucaultiana do discurso, que destaca as relações estabelecidas entre a linguagem e a subjetividade, influenciada pelas ideias de Michel Foucault. Para o autor, o discurso vai além de um processo de comunicação objetivo.; Ele representa uma rede complexa de signos e significados, que ensejam um contexto histórico-social e desvelam realidades sociais e psicológicas. Para Foucault (2008, p. 55), os discursos são mais do que o uso de signos para designar coisas: "é esse mais que os torna irredutíveis à língua e ao ato da fala. É esse 'mais' que é preciso fazer aparecer e que é preciso descrever".

Através dos discursos, relações de poder e controle social são estabelecidos, aprisionando os sujeitos a uma naturalização dessas relações discursivas e a uma reprodução de práticas baseadas no controle e no poder, produzindo subjetividades que operam pelos discursos e os legitimam.

O processo de análise utilizado neste estudo documental baseia-se nos trabalhos de Willig (2010), também empregado por Sykes, Willig e Marks (2004), Traverso-Yépez (2007) e Véras e Traverso-Yépez (2010). Ele se constitui em seis etapas: (1) identificação das construções discursivas presentes no texto; (2) reunião das construções discursivas em discursos mais amplos; (3) compreensão da função e orientação para a ação que o discurso quer alcançar; (4) revelação dos posicionamentos que os atores envolvidos ocupam no documento; (5) estudo das práticas que os posicionamentos dos sujeitos desvelam através das construções discursivas; e (6) aprofundamento das relações existentes entre posicionamentos e processos de subjetivação.

Esses estágios permitem ao pesquisador mapear alguns recursos discursivos utilizados no texto e as posições subjetivas que eles contêm, assim como explorar as suas implicações para a subjetividade e a prática. É necessário que o primeiro autor leia os textos por, pelo menos, quatro vezes na intenção de se tornar familiar e engajado com os textos. Os discursos são identificados e discutidos com o segundo autor. O próximo passo é desenhar um plano de análise utilizando as seis etapas descritas, no intuito de apresentar os discursos identificados no estudo (WILLIG, 2010).

Esse tipo de estudo mostra sua potência de análise a partir da compreensão da linguagem como basilar nas construções sociais e subjetivas, inscrevendo o discurso como forma de poder e condicionamento dos comportamentos dos sujeitos, principalmente na relação entre discurso e instituições, regulamentando práticas culturais e formas de ser e de existir no mundo (WILLIG, 2010). 


\title{
Análise do projeto político pedagógico de licenciatura em pedagogia - noturno
}

Nesta análise, as etapas do método de Willig (2010) são aprofundadas a partir dos discursos contidos no PPP de Licenciatura em Pedagogia e suas relações com as DCNP.

\section{As construções discursivas}

Neste primeiro processo foi analisado o modo como os discursos foram construídos e apresentados no texto. No PPP, os enunciados mostram-se organizados em três construções discursivas principais, a saber: a pesquisa como eixo de formação, a práxis pedagógica na formação e os princípios formativos. Vamos a cada uma delas.

- Apesquisa como eixo de formação

No PPP, a pesquisa é um dos eixos de formação do pedagogo, sendo considerada como um dos principais movimentos para o processo de ensino-aprendizagem nas Licenciaturas. É concebida como possibilidade de consolidar a relação teoria-prática, através do contato com as práticas pedagógicas, vislumbrando a formação de um pedagogo mais crítico e consciente. Podemos observar isso no seguinte trecho:

\begin{abstract}
A proposta de se ensinar pela pesquisa possibilita a formação de um profissional comprometido com o questionamento de sua própria realidade e inconformado com os resultados que se apresentam em sua prática, portanto, um profissional que compreende a realidade em que vive e atua de modo a transformá-la. Além de constituir-se num processo formativo, a pesquisa atrela ao ensino a possibilidade de uma produção e sistematização coletiva do conhecimento através da vivência de processos de ação-reflexão-ação. (PPP - LP).
\end{abstract}

Nas DCNP é descrito que a pesquisa compõe um dos objetos centrais da formação do licenciado, posicionando esta como uma das práticas em que o egresso de Pedagogia deve estar apto (BRASIL, 2006).

A concepção de professor-pesquisador na formação docente é uma apropriação recente, tendo chegado ao Brasil apenas a partir do final da década de 1980 (ANDRÉ, 2005). O movimento ainda não parece ser consensual, existindo propósitos distintos ao uso (FAGUNDES, 2016), porém as teorias sobre o tema mostram-se intimamente ligadas à ideia do professor-reflexivo (NÓVOA, 2001):

O professor pesquisador e o professor reflexivo, no fundo, correspondem a correntes diferentes para dizer a mesma coisa. São nomes distintos, maneiras diferentes dos teóricos da literatura pedagógica abordarem uma mesma realidade. A realidade é que o professor pesquisador é aquele que pesquisa ou que reflete sobre a sua prática. Portanto, aqui estamos dentro do paradigma do professor reflexivo. É evidente que podemos encontrar dezenas de textos para explicar a diferença entre esses conceitos, mas creio que, no fundo, no fundo, eles fazem parte de um mesmo movimento de preocupação com um professor que é um professor indagador, que é um professor que 
assume a sua própria realidade escolar como um objeto de pesquisa, como objeto de reflexão, como objeto de análise. (NÓVOA, 2001, [s.p.]).

Para Fagundes (2016), o professor-pesquisador e o professor-reflexivo foram concebidos em circunstâncias diferentes e com objetivos distintos, demandando um cuidado analítico que busque desvelar as ideologias e as filosofias a que subjazem tais compreensões, principalmente decorrente do alinhamento da concepção de professor-reflexivo a um projeto de formação neoliberal, caracterizado pelo aligeiramento (ARCE, 2001) e pela responsabilização quase que exclusiva do professor aos processos educacionais.

Para Schön (2000), um dos principais autores nesse tema, a concepção de professor-reflexivo supera a compreensão tecnicista de que o professor recebe e transmite conhecimentos, ele passa a ser visto como produtor de conhecimentos, e que são advindos da sua prática reflexiva. Essa prática baseia-se na valorização dos conhecimentos tácitos, no diálogo entre os atores envolvidos e na articulação da teoria com a prática, construindo a reflexão-na-ação.

O modelo defendido por Schön parece assemelhar-se às proposições do $\mathrm{PPP}$, seguindo um movimento presente na educação brasileira, conforme aponta $\mathrm{Pi}$ menta (2012), que critica a falta de problematização das teorias incorporadas às políticas educacionais, caracterizando-se como um discurso retórico e favorecedor da desresponsabilização do governo nessas políticas, já que o foco volta-se ao docente e às suas práticas.

Essa retórica pode ser observada no PPP, pois apesar da concepção de pesquisa estar atrelada à ideia do professor-reflexivo, não há uma discussão aprofundada sobre o tema professor-pesquisador/professor-reflexivo. O documento carece de maior esclarecimento sobre o que se entende como pesquisa e como proceder à sua prática A despeito de regularem componentes curriculares com o propósito de desenvolverem essa competência, não há uma problematização dos métodos e dos contextos em que a pesquisa possa ser refletida e ampliada enquanto prática.

- A práxis pedagógica na formação

O outro eixo de formação do curso são as novas tecnologias e práxis pedagógica, contudo a discussão sobre novas tecnologias mostra-se incipiente, diferentemente da notoriedade dada ao tema da práxis pedagógica.

Esse conceito emerge no texto como um espaço da formação docente em ato, profissionalizando o licenciado. A concepção da práxis pedagógica da formação em Licenciatura é uma discussão pertinente à construção das DCNP (BRASIL, 2006), já que diversos poderes instituintes buscaram a formação do pedagogo como licenciado, através da construção de uma identidade de professor, e não somente de uma de técnico.

Entende-se, dessa forma, que a docência se constitui como um dos processos centrais no PPP. Este associa a práxis pedagógica à pesquisa, em consonância com 
o proposto por Aguiar e Melo (2005, p. 127), que considera a docência como “[...] uma das mediações para a construção do discurso de síntese da Pedagogia, articulada intrinsecamente com a pesquisa".

Nesse excerto do documento, observam-se a reiterada importância da pesquisa na formação do licenciado e sua articulação com a práxis pedagógica:

[...]o eixo da Práxis Pedagógica é extremamente valorizado nas atividades que comportam a docência compartilhada como dimensão estruturante do ato de pesquisar. (PPP - LP).

Novamente percebe-se a ênfase na pesquisa para a formação acadêmica, destacando a docência compartilhada como um elemento estruturador da ação de pesquisar, denotando a este eixo uma característica participativa e coletiva, que se constitui através de experiências compartilhadas na docência e na pesquisa, e de relações horizontalizadas entre alunos e professores (PPP - LP).

A articulação entre a práxis pedagógica e a pesquisa tem sido apontada como fundamental, principalmente no debate sobre o professor-pesquisador e o professor-reflexivo, já que, de forma geral, a postura questionadora e investigativa das práticas pedagógicas é construída a partir de ações de pesquisa e de reflexões sobre o ambiente de trabalho, tornando a pesquisa e a práxis pedagógica interfaces do mesmo processo (NUNES, 2008). Como descrito no item anterior, o PPP baseia-se no perfil de um professor-pesquisador e vincula essa dimensão com a prática pedagógica. Contudo, o desenvolvimento dessa relação também demanda maior aprofundamento teórico e metodológico no PPP.

\section{- Os principios formativos}

Essa construção discursiva foi identificada a partir da descrição de diversos princípios norteadores em diferentes tópicos do documento. Tais princípios versam sobre valores e objetivos curriculares que orientam e caracterizam uma identidade pretendida do licenciado. Alguns desses princípios são: horizontalidade, emancipação, empoderamento, transformação, trabalho pedagógico, desenvolvimento da pesquisa, docência compartilhada, trabalho interdisciplinar, relação teoria-prática flexibilização curricular, aprendizagem cooperativa e dialógica (PPP - LP). Nas DCNP, alguns desses princípios são valorizados, como a interdisciplinaridade, a ideia de democratização, pertinência e relevância social, relação teoria-prática e a promoção do diálogo (BRASIL, 2006).

No item "Objetivos" do PPP é retratado alguns desses princípios:

A proposta pedagógica do curso de Licenciatura em pedagogia foi inspirada em quatro princípios básicos: horizontalidade, emancipação, empoderamento e transformação. Tais princípios foram construídos em diálogos e audiências públicas com a comunidade acadêmica e com a comunidade local, representantes da SME e principalmente longas discussões em plenárias do Centro. Esses princípios têm como objetivo:

- Formar pedagogos e pedagogas, professores/ras que tenham o trabalho pedagógico como sentido da formação; 
- Empenhar esforços para que o curso proporcione uma sólida formação teórica;

- Desenvolver a pesquisa como forma de conhecimento e intervenção na realidade social;

- Propiciar junto a comunidade escolar um trabalho partilhado e coletivo através da docência compartilhada;

- Realizar um trabalho interdisciplinar que permita uma visão ampla de conhecimento e da educação;

- Buscar estratégias que favoreçam uma maior articulação entre a teoria e a prática;

- Garantir flexibilidade curricular e estratégias de auto avaliação constantes em relação a proposta pedagógica. (PPP - LP).

A construção do discurso, quanto a esses princípios, revela um paradigma de formação que busca superar a racionalidade técnica, buscando a primazia das relações culturais e sociais que perpassam o ato formativo.

Para o PPP, estabelecer esses princípios “[...] não garante por si só ações que viabilizem práticas curriculares consonantes com essas ações pensadas, entretanto dessas discussões brotaram componentes curriculares, atividades articuladoras e projetos de docência compartilhada" (PPP - LP). Dessa forma, através dos eixos e atividades propostas, tais princípios poderão ser desenvolvidos. Porém, a garantia desses direitos poderia efetivar-se não somente com as atividades curriculares obrigatórias, mas com a ampliação da perspectiva formativa, para além da formação linear dos discentes. Poderiam ser analisadas ações no âmbito da formação continuada dos docentes-formadores, propondo tanto uma atualização dos conhecimentos frente às demandas do curso, como estender a avaliação e reformulações do PPP à comunidade local, tanto a acadêmica como a não-acadêmica, viabilizando a participação desta no planejamento de atividades, protagonizando-a na formação de que terão usufruto.

Nesse sentido, é importante alertar-se para a necessidade da contínua discussão e da atualização desses princípios, a fim de que eles correspondam às expectativas da comunidade e do ambiente envolvido, abrindo espaços para aprofundar novos objetivos e métodos que deem sentido a essa formação.

\section{Tipos de discurso}

Nessa etapa são apresentados os juízos de valor contidos nas construções discursivas, compreendendo o viés que esses discursos carregam (TRAVERSO -YÉPEZ, 2007). Com a leitura do PPP é possível constatar que ele cumpre seu papel normativo, pois funciona como documento que prescreve e indica como acontecerá a formação de Licenciatura em Pedagogia, descrevendo os componentes curriculares, atividades complementares, o papel dos professores, dos alunos e do colegiado acadêmico, além de indicar que sua constituição deriva e se mantém de acordo com as leis e resoluções institucionais. 
Dessa forma, um tipo de discurso marcante no texto é o prescritivo-normativo da formação. Em grande parte das construções discursivas percebe-se um discurso que se constitui enquanto norma, prescrevendo como a formação ocorrerá e reproduzindo o que é previsto nas DCNP:

O curso de Licenciatura em Pedagogia ofertado no turno noturno [...], respeitando o perfil profissiográfico traçado, formará o Licenciado em Pedagogia para atuar em instituições escolares e não-escolares na docência em educação infantil; no ensino básico nos anos iniciais do ensino fundamental e nas matérias de formação pedagógica, bem como na gestão educacional. (PPP - LP)

Art. $4^{\circ} \mathrm{O}$ curso de Licenciatura em Pedagogia destina-se à formação de professores para exercer funções de magistério na Educação Infantil e nos anos iniciais do Ensino Fundamental, nos cursos de Ensino Médio, na modalidade Normal, de Educação Profissional na área de serviços e apoio escolar e em outras áreas nas quais sejam previstos conhecimentos pedagógicos. (BRASIL, 2006)

As Diretrizes têm sido consideradas como ambíguas para alguns autores (DURLI, 2007; SAVIANI, 2007), devido à tentativa de agrupar projetos formativos distintos que estavam em disputa quando da sua criação, trazendo características que atendiam o projeto das entidades e movimentos sociais da educação, como das propostas já implementadas pelas políticas públicas nos anos 90 (FREITAS, 2002). Dessa forma, é necessário repensar sobre como os projetos de curso interpretaram tal resolução, e como os cursos vêm implementando as modificações indicadas, evitando que haja uma reprodução irrefletida sobre as proposições do documento (HOBOLD et al., 2009). Segundo Saviani (2007, p. 128), para além das DCNP, os cursos de Pedagogia precisam "[...] se colocar na perspectiva de uma saída para a crise do modelo tradicional de escola visando à construção de um novo modelo, adequado às novas condições próprias da sociedade atual".

Desse modo, a presença de um discurso prescritivo-normativo assume as obrigações curriculares que a resolução designa, mas traz à luz a importância de posicionar o PPP frente ao documento nacional, apontando as características próprias do curso, diante do cenário das discussões na formação de professores.

Outro tipo de discurso que emerge é o de compromisso e transformação social, trazendo referências ao contexto local e regional onde está localizada a universidade, com destaque ao turno noturno, no qual o curso funcionará. No texto apresentamse as contingências de criação da universidade e do centro onde está lotado o curso, dissertando sobre a realidade educacional da região e a importância de cursos de Licenciatura para tal contexto. O diálogo sobre a identidade e a formação do pedagogo adentram na possibilidade de um curso noturno e no compromisso sócio-político-cultural da instituição com a região.

O ensino noturno no país ocupa uma grande parcela no número de matrículas presenciais, tendo uma taxa de crescimento anual maior do que nos cursos de turno diurno (TERRIBILI FILHO; NERY, 2009). No Censo da Educação Superior de 2013, 63,1\% dos alunos de cursos presenciais estavam matriculados no ensino noturno, 
indicando que a maioria dessas matrículas ocorre nesse turno. Quando analisado o tipo de instituição, verifica-se uma grande disparidade, tendo a instituição privada $73 \%$ de suas matrículas no turno noturno, enquanto que as universidades federais possuem 70\% das matrículas no diurno (INEP, 2013). Ainda com relação a informações estatísticas, no Censo de 2014 é demonstrado que os cursos de Licenciatura também estão em maior número nas instituições privadas, com 58,8\% das matrículas, enquanto as públicas possuíam $41,2 \%$ (INEP, 2014).

Partindo dessa conjuntura, constata-se a relevância das instituições públicas de ensino discutirem quais suas propostas formativas para o ensino noturno e para as Licenciaturas, visando identificar as problemáticas que caracterizam a oferta desse ensino e como solucionar e garantir que o ensino público alcance o estudante-trabalhador e o campo da formação de professores (BARREIRO; TERRIBILI FILHO, 2007).

Nesse sentido, o discurso de compromisso e de transformação social do PPP parece estar consonante com essa discussão, propondo um curso de Licenciatura no turno noturno, preocupado em garantir que o trabalhador possa ter acesso ao ensino gratuito e que possa ser protagonista no seu contexto social.

O discurso de compromisso e transformação social também é presente nas DCNP, constatando que o PPP assume similaridades com a resolução, mas impõe aspectos que são inerentes à constituição do curso, como a demanda pela criação de um curso noturno na região.

\section{Orientação para ação}

A orientação para ação indica os objetivos que as construções discursivas tentam atingir (TRAVERSO-YÉPEZ, 2007), desvelando as intencionalidades representadas no texto. Tanto no que se refere ao discurso normativo quanto ao discurso de compromisso social, ambos orientam para um currículo instituído, que normatiza o processo formativo. As regulações curriculares ocorrem a partir da criação da matriz curricular, da definição dos componentes curriculares, da carga horária e dos deveres e funções dos atores envolvidos. Essa normatização segue os procedimentos indicados nas Diretrizes (BRASIL, 2006):

Art. $7^{\circ} \mathrm{O}$ curso de Licenciatura em Pedagogia terá a carga horária mínima de 3.200 horas de efetivo trabalho acadêmico, assim distribuídas:

I - 2.800 horas dedicadas às atividades formativas como assistência a aulas, realização de seminários, participação na realização de pesquisas, consultas a bibliotecas e centros de documentação, visitas a instituições educacionais e culturais, atividades práticas de diferente natureza, participação em grupos cooperativos de estudos;

II - 300 horas dedicadas ao Estágio Supervisionado prioritariamente em Educação Infantil e nos anos iniciais do Ensino Fundamental, contemplando também outras áreas específicas, se for o caso, conforme o projeto pedagógico da instituição;

III - 100 horas de atividades teórico-práticas de aprofundamento 
em áreas específicas de interesse dos alunos, por meio, da iniciação científica, da extensão e da monitoria. (BRASIL, 2006).

DCNP:

No trecho abaixo, o PPP descreve as normas curriculares baseadas nas

O curso será desenvolvido no turno noturno em um mínimo de 4 anos e máximo de 6 anos com carga horária total de 3.194 horas, em caráter presencial e semestral. O aluno matricular-se-á no Curso de Licenciatura em Pedagogia (Noturno) observando a seqüência das atividades curriculares estabelecidas pelo Colegiado do Curso. Para integralização do currículo do curso o aluno deverá ter concluído 3.194 horas, assim distribuídas: 1.853 horas na Perspectiva Básica, 884 horas na Perspectiva Específica e 306 horas na Perspectiva Eletiva. Vale ressaltar que o educando terá que cumprir 306 horas de estágio, porém estas estão distribuídas nos componentes da perspectiva básica e específica do curso. (PPP - LP).

Quando os textos referem-se a carga horária definida e a outras obrigações, observa-se a reprodução da norma estabelecida no documento de nível nacional, mostrando o cumprimento das Diretrizes Curriculares Nacionais, que funcionam como orientador para todos os cursos no país.

\section{Posicionamentos}

Nessa etapa observamos de que forma as construções discursivas posicionam os atores sociais implicados (TRAVERSO-YÉPEZ, 2007). Willig (2010) aborda sobre um posicionamento subjetivo, superando a ideia de desempenhar um papel, pois atravessa a constituição dos sujeitos e das suas subjetividades. A partir do documento, elencamos os atores em três categorias: os alunos; os docentes e o colegiado do curso, e a comunidade.

Um posicionamento passivo é observado nos discursos, caracterizando os alunos como sujeitos a cumprir requisitos curriculares e a aprender e exercer determinados valores apregoados no PPP, o que coaduna com o propósito desse documento: prescrever essa formação.

Destaca-se que, quando o documento se refere à avaliação do PPP, observase uma horizontalidade entre alunos e docentes, mostrando um coletivo nesse processo e reforçando os princípios formativos trazidos anteriormente.

Outro aspecto importante a ser ressaltado é que o curso acontece em turno noturno, o que requer a criação de uma matriz curricular voltada para as especificidades do aluno trabalhador, avaliando e adaptando a carga horária das aulas, estágios, participação em atividades de pesquisa e extensão e acesso à infraestrutura de todos os setores da universidade, como biblioteca, transporte, segurança e atendimento administrativo (MARANHÃO; VERAS, 2017).

Analisando tais especificidades, é fundamental posicionar os alunos e professores como ativos nesse Projeto, permitindo o desenvolvimento de um curso que atenda às necessidades desse público, garantindo que todas as condições de formação 
previstas ocorram plenamente. Ressalta-se que tais características não são descritas no PPP, o que dá margem a questionamentos acerca da presença destas no curso, e reitera-se a importância de dar destaque aos discentes na construção do projeto formativo.

Os docentes e o colegiado do curso são também posicionados com relação às suas funções no curso. O colegiado como órgão que cria e desenvolve as atividades a serem cumpridas pelos alunos e os docentes como um conjunto que colabora para que esses requisitos curriculares ocorram conforme o prescrito. Esses discursos, dessa forma, enfatizam o papel legal dos docentes.

As DCNP (BRASIL, 2006), enquanto marco regulamentário, destinam-se aos gestores universitários, a fim de que esses possam organizar o funcionamento dos cursos em consonância às previsões estabelecidas. Assim, reproduz-se no PPP um tipo de discurso hierárquico, baseado nas prerrogativas nacionais sobre a formação em Pedagogia, que acarretam em posicionamentos normativos atravessados por uma lógica unívoca de formação.

Com relação à comunidade, esta é citada apenas no artigo $5^{\circ}$, inciso VIII das DCNP (BRASIL, 2006), e é descrita como um espaço no qual o licenciando deve promover e facilitar relações de cooperação, juntamente com a instituição educativa e a com a família. No PPP, a comunidade também é pouco citada, sendo posicionada como um grupo que participará das audiências públicas sobre o curso ou como um campo de atuação do graduando. A ideia de comunidade escolar está mais presente no PPP, posicionada como lócus de prática e estágio docente (PPP - LP), indicando que o documento privilegia o espaço escolar na formação. A partir desse dado, é possível levantar a hipótese de que o curso prioriza uma formação voltada à docência no ensino básico, posicionando-se frente à proposta das DCNP, que versa sobre o enfoque ampliado da formação docente, compreendendo espaços escolares, de pesquisa e de gestão educacional.

O discurso sobre a comunidade indica o interesse do PPP sobre esta, porém ainda parece ser uma relação superficial, que não problematiza ou demarca o papel que esta pode ter na construção e na avaliação do curso, passando a vê-la, muitas vezes, apenas como campo de estágio.

Urge a necessidade de refletir sobre o espaço da comunidade no Projeto, sobre o conceito de extensão universitária para esse currículo e as possíveis relações entre a comunidade, a pesquisa e o ensino, problematizando melhor a díade comunidade-universidade nos eixos curriculares e princípios formativos do curso. A extensão universitária tem sido caracterizada por uma concepção muitas vezes fragmentada, de caráter aplicacionista, sendo entendida como transmissora de conhecimentos, impedindo que a mesma tenha um espaço contínuo e de destaque nas políticas universitárias (MELO NETO, 2003). Conforme Melo Neto (2003), a extensão universitária precisa ser considerada como uma ação deliberada, que indique sua intenção na produção de conhecimento voltado à transformação social, o que implica o compromisso da universidade em acompanhar os movimentos da sociedade e as demandas que ela impõe. 
No contexto da formação de professores, é necessário reafirmar o papel da universidade diante das escolas de ensino básico, fortalecendo a indissociabilidade do ensino-pesquisa-extensão nos contextos legítimos do trabalho docente. Gatti (1992) analisa que as universidades não têm efetivado o seu papel social nos outros níveis de ensino, que poderia ocorrer através de pesquisas educacionais, incentivo na formação continuada e valorização dos cursos de Licenciatura. Zeichner (2010) também aponta para esse discurso, indicando as relevantes contribuições que as interseções universidade-escola podem proporcionar à formação de professores, através de programas que objetivem o compartilhamento de saberes entre os docentes do ensino básico, do ensino superior e os graduandos.

\section{Práticas}

As práticas remontam à forma que as construções discursivas implementam comportamentos e ações direcionados aos atores sociais e a seus posicionamentos (VÉRAS; TRAVERSO-YÉPEZ, 2010).

As práticas identificadas nos discursos atinam para os modos de fazer o currículo de Licenciatura em Pedagogia: a pesquisa, as disciplinas curriculares, o estágio e os processos de avaliação (disciplinares e do próprio $\mathrm{PPP}$ ). Tais práticas têm caráter regulatório, adentrando o discurso prescritivo-normativo, relacionando-se à determinação das práticas aos sujeitos, posicionando-os de forma passiva frente às obrigações legais de funcionamento do curso. Entretanto, podemos destacar que alguns desses componentes curriculares mostram-se mais flexíveis, possibilitando aos licenciandos e docentes forjarem uma trajetória formativa menos prescritiva e linear. Os componentes "Unidades temáticas" - presentes em todos os semestres curriculares - cumprem esse objetivo, nos quais temas de interesse dos alunos são incorporados à trajetória acadêmica, favorecendo a flexibilidade curricular e aproximando o curso das necessidades sociais e profissionais (PPP - LP).

Considera-se de extrema relevância a oferta de componentes que prevejam os objetivos traçados nessa formação, contudo o PPP aponta para um perfil profissional vinculado à transformação social e questiona se um componente pode atender a tais pretensões. Certamente o componente contribui fortemente nessa proposta, mas não pode garantir sozinho o cumprimento das intenções formativas voltadas à autonomia e à flexibilização curricular. Nessa reflexão, ratifica-se a necessidade de adaptar as práticas curriculares ao ensino noturno, refletindo e discutindo possíveis dispositivos que colaborem na permanência e no sucesso acadêmico dos estudantes-trabalhadores, atuando diretamente na consolidação de um projeto voltado à transformação social.

\section{Processos de subjetivação}

A última etapa considera a relação dinâmica entre os posicionamentos e as práticas e os processos de subjetivação (TRAVERSO-YÉPEZ, 2007), partindo da compreensão de que o texto não é neutro, e, sim permeado por construções que posicionam sujeitos a partir de determinados objetos e práticas. Tais processos constituem realidades sociais e psicológicas, encenando formas de ser e estar no mundo (WILLIG, 2010). 
Os processos de subjetivação dos sujeitos revelam-se através dos posicionamentos e das práticas a que são delegados, indicando o cumprimento da norma e dos princípios prescritos no Projeto.

O PPP, ao posicionar passivamente a escola e a comunidade, descrevendo a primeira como um espaço para o estágio, diverge dos valores formativos trazidos no documento, referentes a uma formação emancipadora e transformadora da realidade (PPP - LP), configurando processos de subjetivação marcados por relações instituídas e estreitas possibilidades de diálogo. Os posicionamentos dos atores sociais no texto sinalizam que estão estruturados pela lógica disciplinar, obedientes a normas e ordens pré-estabelecidas no documento, demonstrando uma passividade e pouco incentivo ao protagonismo dos sujeitos na execução e na construção do curso. As posições subjetivas nos alertam para os efeitos que os enunciados discursivos provocam, indicando um sistema de relações e sentidos que se constituem no e pelo discurso, no qual podem ser "[...] determinadas a dispersão do sujeito e sua descontinuidade em relação a si mesmo" (FOUCAULT, 2007, p. 61).

A descontinuidade é evidenciada na fragmentação e distanciamento dos discursos contidos no PPP, que retrata a preocupação em uma formação crítica, mas não destaca o papel social dos alunos, docentes e da comunidade perante essa formação. Esse distanciamento fragiliza algumas concepções e considerações do PPP sobre o processo formativo, já que as intenções pedagógicas não estão totalmente vinculadas aos posicionamentos dos atores.

Esses posicionamentos traduzem uma perspectiva de compreensão sobre as relações no curso de Pedagogia, e se caracterizam através do poder instituído do PPP, que regula previamente comportamentos, reduzindo as ações dos atores sociais aos cumprimentos normativos do documento. Esse reducionismo pode gerar consequências nas relações que os atores estabelecem com o curso e a formação, afetando os processos subjetivos desses sujeitos.

\section{Outras considerações e reflexões}

O tensionamento histórico na construção das DCNP evidencia as problemáticas e lacunas da pauta sobre a formação de professores no país e como estas repercutem nos modelos e nas propostas de formação atual. Para Gatti (2014) as Diretrizes Curriculares Nacionais de diferentes Licenciaturas não têm sido suficientes para o desenvolvimento de uma nova ordenação curricular, o que demanda uma melhor estruturação, qualificação e avaliação do trabalho feito nesses cursos, buscando uma "[...] verdadeira revolução nas estruturas institucionais formativas e nos currículos de formação"(GATTI, 2010, p. 1375).

Ressalta-se que diversos aspectos do Projeto analisado coadunam com os avanços postos pelas DCNP e pelas discussões instituintes, como o foco para a formação docente, a importância dada ao professor-pesquisador-reflexivo, a possibilidade de flexibilidade curricular e a valorização da identidade "professor". Contudo, ainda se reproduzem questões que continuam a demandar maior elaboração e aprofundamento, 
como a relação escola-universidade, a extensão universitária e a participação dos alunos e professores na construção do curso.

Destaca-se que a escolha pelo método da análise foucaultiana do discurso, relaciona-se à complexidade de informações que as etapas proporcionam ao pesquisador, trazendo ao leitor uma perspectiva reflexiva sobre os enunciados presentes no documento, despertando para as práticas instaladas pela linguagem. A análise feita compreende os discursos que se fazem presentes no texto. Assim, toda a discussão se refere ao que é posto enquanto norma e documento institucional. As realidades construídas, em consequência desses discursos, ou de outros documentos que fizeram contribuições ao PPP, não foram objeto de estudo, e podem evidenciar elementos que contradigam ou reafirmem os enunciados. Esse aspecto fragiliza o estudo, contudo entende-se que o texto ativa práticas institucionais e organiza condições nas quais experiências acontecem (WILLIG, 2010).

A análise do Projeto Político Pedagógico torna-se interessante quando o entendemos enquanto "[...] resultante de uma história refletida ou de uma experiência institucional problematizada pela cultura educacional, suas tradições e finalidades" (MACEDO, 2005, p. 130), representando não apenas uma forma de regulação, mas um instrumento que retrata a visão de mundo e indivíduo que a instituição tenta alcançar, anunciando a sua constituição política e histórica. Por essa característica, Macedo (2005) destaca que esse dispositivo exige a necessidade de sua contínua problematização e atualização, analisando suas interfaces frente a uma visão cosmológica, antropossocial, epistemológica, ético-política, didático-pedagógica, técnico-profissional e senso-estética.

$\mathrm{O}$ presente artigo mostrou que o PPP analisado atende às normas previstas pelas DCNP, mantendo o discurso prescritivo, que reflete nos posicionamentos dados aos sujeitos, marcados pelo pouco protagonismo no curso. Ainda que os valores formativos descrevam a importância dessa questão, o papel dos alunos, professores e comunidade pode ganhar mais espaço na proposta político-pedagógica, tornando a ação destes um norteador para a construção dos eixos formativos, para o desenvolvimento das especificidades de um curso noturno e para a avaliação das normas previstas, possibilitando movimento e transformação ao Projeto.

\section{Referências}

AGUIAR, Márcia Ângela da Silva et al. Diretrizes curriculares nacionais do curso de pedagogia no Brasil: disputas de projetos no campo da formação do profissional da educação. Educação \& Sociedade, Campinas, v. 27, n. ${ }^{\circ}$ 96, Especial, p. 819-842, out. 2006.

AGUIAR, Márcia Ângela da Silva; MELO, Márcia Maria de Oliveira. Pedagogia e diretrizes curriculares: polêmicas e controvérsias. Linhas Críticas, Brasília, v. 11, n. ${ }^{\circ}$ 20, p. 119-138, jan.jun. 2005.

ANDRÉ, Marli Eliza. Pesquisa, formação e prática docente. In: ANDRÉ, Marli Eliza. (Org.). O papel da pesquisa na formação e na prática dos professores. 4. ed. São Paulo: Papirus, 2005. p. 55-67.

ARCE, Alessandra. Compre um kit neoliberal para a educação infantil e ganhe grátis os dez passos para se tornar um professor reflexivo. Educação \& Sociedade, Campinas, v. 22, n. ${ }^{\circ}$ 74, p. 251-283, abr. 2001. 
BARREIRO, Iraíde Marques de Freitas; TERRIBILI FILHO, Armando. Educação superior no período noturno no Brasil: políticas, intenções e omissões. Ensaio: aval. pol. públ. Educ., Rio de Janeiro, v.15, n. 54, p.81-102, jan./mar., 2007.

BRASIL. Presidência da República. Subchefia para Assuntos Jurídicos. Lei n.o 9394/96, de 20/12/1996. Estabelece as diretrizes e bases da educação nacional. Diário Oficial da União, Brasília, DF, 23 dez. 1996, p. 27833.

BRASIL. Decreto n.o 3.276, de 6 de dezembro de 1999. Dispõe sobre a formação em nível superior de professores para atuar na educação básica, e dá outras providências. Diário Oficial da União, Brasília, DF, 07 dez. 1999, p. 4.

BRASIL. Decreto n.o 3554, de 7 de agosto de 2000. Dá nova redação ao $§ 2^{\circ}$ do art. 3 do Decreto n. ${ }^{\circ} 3.276$, de 6 de dezembro de 1999, que dispõe sobre a formação em nível superior de professores para atuar na educação básica, e dá outras providências. Diário Oficial da União, Brasília, DF, 8 de ago. 2000, Seção 1, p.1.

BRASIL. Parecer CNE/CP n. ${ }^{\circ}$ 5, 13.12.2005. Diretrizes Curriculares Nacionais para o Curso de Pedagogia. Brasília, 2005. Disponível em: <http://portal.mec.gov.br/cne/arquivos/pdf/ pcp05_05.pdf>. Acesso em: 13 mai. 2016.

BRASIL. Parecer CNE/CP n. 3/2006. Reexame do Parecer CNE/CP no 5/2005, que trata das Diretrizes Curriculares Nacionais para o Curso de Pedagogia. Disponível em: <http://portal. mec.gov.br/cne/arquivos/pdf/pcp003_06.pdf>. Acesso em: 13 mai. 2016.

BRASIL. Conselho Pleno. Resolução CNE/CP n. ${ }^{\circ}$, de 15 de maio de 2006. Institui Diretrizes Curriculares Nacionais para o Curso de Graduação em Pedagogia, Licenciatura. Diário Oficial da União, Brasília, DF, 16 mai. 2006, Seção 1, p. 11.

BRZEZINSKI, Iria. Formação de professores para a educação básica e o curso de pedagogia: a tensão entre instituído e instituinte. Revista Brasileira de Política e Administração da Educação, v. 23, n. ${ }^{\circ}$ 2, p. 229-251, mai.ago. 2007.

BRZEZINSKI, Iria. Novas diretrizes curriculares nacionais da pedagogia. In: MOROSINI, M. C. (ed.). Enciclopédia de Pedagogia Universitária - Glossário, v. 2. Instituto Nacional de Estudos e Pesquisas Educacionais Anísio Teixeira (INEP): Brasília, 2006.

BRZEZINSKI, Iria. Pedagogo: Delineando Identidade(s). Revista UFG, ano 13, n. ${ }^{\circ}$ 10, p. 120-132, jul. 2011.Disponível em: <https://www.proec.ufg.br/up/694/o/10_iria_brzezinski. pdf>. Acesso em: 29 abr. 2018

CABRAL NETO, Antônio. Notas para uma discussão contextualizada sobre o projeto político-pedagógico. In: ALMEIDA, Maria Doninha. (Org.) Projeto Político-Pedagógico. Col. Pedagógica - 1,2. ed. Natal, RN: EDUFRN, 2004.

DURLI, Zenilde. $O$ processo de construção das diretrizes curriculares nacionais para o curso de pedagogia: concepções em disputa. 2007. 226 f. Tese (Doutorado em Educação). Centro de Ciências da Educação. Universidade Federal de Santa Catarina, Florianópolis, 2007.

FAGUNDES, Tatiana Bezerra. Os conceitos de professor pesquisador e professor reflexivo: perspectivas do trabalho docente. Revista Brasileira de Educação, v. 21, n. ${ }^{\circ}$ 65, abr.-jun. 2016.

FERREIRA, Maria Salonilde. A díade político-pedagógica. In: ALMEIDA, Maria Doninha (org.) Projeto Político-Pedagógico. Col. Pedagógica - 1, 2. ed. Natal, RN: EDUFRN, 2004.

FÓRUM DE PRÓ-REITORES DE GRADUAÇÃO DAS UNIVERSIDADES BRASILEIRAS. ForGRAD. Do pessimismo da razão para o otimismo da vontade: referências para a construção dos projetos pedagógicos na IES brasileiras. Curitiba, 1999. Disponível em: <http://antigo.enap.gov.br/downloads/ec43ea4fMatProfDanielXimenes2.pdf>. Acesso em: 08 mar. 2017.

FOUCAULT, Michel. A arqueologia do saber. 7. ed. Rio de Janeiro: Forense Universitária, 2008. 
FREITAS, Helena Costa Lopes. Formação de professores no Brasil: 10 anos de embate entre projetos de formação. Educ. Soc., Campinas, vol. 23, nº. 80, p. 136-167, set. 2002.

GATTI, Bernadete Angelina. A formação dos docentes: o confronto necessário professor x academia. Cad. Pesq., n.81, p.70-74, mai. 1992. Disponível em: <http://publicacoes.fcc.org.br/ ojs/index.php/cp/article/view/993/>. Acesso em: 01 abr. 2018.

GATTI, Bernadete Angelina. A formação inicial de professores para a educação básica: as licenciaturas. Revista USP, São Paulo, n. ${ }^{\circ}$ 100, p. 33-46, dez.- jan.- fev. 2013-2014.

GATTI, Bernadete Angelina. Formação de professores no Brasil: características e problemas. Educação \& Sociedade, Campinas, v. 31, n. ${ }^{\circ}$ 113, p. 1355-1379, out.-dez. 2010.

HOBOLD, Márcia et al. As diretrizes curriculares nacionais dos cursos de pedagogia para a formação docente: processo de implantação da Resolução CNE/CP n. o 1/2006. Psic. da Ed., São Paulo, n.o 28, p. 151-168, jun. 2009.

INEP - INSTITUTO NACIONAL DE ESTUDOS E PESQUISAS EDUCACIONAIS ANÍSIO TEIXEIRA. Censo da educação superior 2013. Brasília: Ministério da Educação INEP, 2013.

INEP - INSTITUTO NACIONAL DE ESTUDOS E PESQUISAS EDUCACIONAIS ANÍSIO TEIXEIRA. Censo da educação superior 2014 - Notas estatísticas. Brasília: Ministério da Educação - INEP, 2014.

MACEDO, Roberto Sidnei. Chrysallis, currículo e complexidade: a perspectiva crítico-multirreferencial e o currículo contemporâneo. 1. ed. Salvador: EDUFBA, 2005.

MARANHÃO, Jucilene Dias; VERAS, Renata Meira. O ensino noturno na Universidade Federal da Bahia: percepções dos estudantes. Ensaio: aval. pol. públ. Educ., v. 25, n. 96, p. 553-584, 2017.

MELO NETO, José Francisco. Extensão universitária e produção do conhecimento. Conceitos, João Pessoa - PB, v. 5, n.9, p. 13-19, 2003.

NÓVOA, António. O professor pesquisador e reflexivo. TV Escola, 13 de set. 2001. Entrevista concedida ao programa Salto para o futuro. Disponível em: <http://tvescola.mec.gov.br/tve/ salto-acervo/interview?idInterview=8283 >. Acesso em: 27 fev. 2017.

NUNES, Debora R. P.Teoria, pesquisa e prática em Educação: a formação do professor-pesquisador. Educação e Pesquisa, São Paulo, v.34, nº.1, p. 97-107, jan.-abr. 2008.

PIMENTA, Selma Garrido. Professor reflexivo: construindo uma crítica. In: PIMENTA, S. G.; GHEDIN, E. (Org.) Professor reflexivo no Brasil: gênese e crítica de um conceito. 7a ed., São Paulo: Cortez, 2012, p. 20-62.

SAVIANI, Dermeval. O espaço acadêmico da Pedagogia no Brasil: perspectiva histórica. Paidéia, v. 14, n. ${ }^{\circ}$ 28, p. 113-124, 2004.

SAVIANI, Dermeval. Pedagogia: o espaço da educação na universidade. Cadernos de Pesquisa, v. 37, n. ${ }^{\circ} 130$, p. 99-134, jan.-abr. 2007.

SCHEIBE, Leda; AGUIAR, Márcia Ângela. Formação de profissionais da educação no Brasil: o curso de pedagogia em questão. Educação \& Sociedade, ano 20, n. ${ }^{\circ}$ 68, dez. 1999.

SCHEIBE, Leda; DURLI, Zenilde. Curso de pedagogia no Brasil: olhando o passado, compreendendo o presente. Educação em foco, v. 14, n. ${ }^{0}$ 17, p. 79-109, jul. 2011.

SCHÖN, Donald. Educando o profissional reflexivo: um novo design para o ensino e a aprendizagem. Porto Alegre: Artes Médicas, 2000.

SILVA, Carmem Silvia Bissolli. Curso de pedagogia no Brasil: história e identidade. São Paulo: Autores associados, 1999. 
SILVA, Heloiza Henê Marinho. Subsídios para a elaboração do Projeto Político-Pedagógico. In: ALMEIDA, Maria Doninha (Org.) Projeto Político-Pedagógico. Col. Pedagógica - 1, 2. ed. Natal, RN: EDUFRN, 2004.

SYKES, Catherine Marie; WILLIG, Carla; MARKS, David. F. Discourses in the European Commission's 1996-2000 Health Promotion Programme. Journal of Health Psychology,. v. 9 , n. ${ }^{\circ} 1$, p. 131-41, 2004.

TERRIBILI FILHO, Armando; NERY, Ana Clara Bortoleto. Ensino superior noturno no Brasil: história, atores e políticas. RBPAE, v. 25, n. 1, p. 61-81, 2009. Disponível em: <http:// seer.ufrgs.br/rbpae/article/view/19327 >. Acesso em: 30 abr. 2018.

TRAVERSO-YÉPEZ, Martha. A. Dilemas na promoção da saúde no Brasil: reflexões em torno da política nacional. Interface - Comunicação, Saúde, Educação, Botucatu, v. 11, n.o 22, p. 223-238, mai.-ago. 2007.

VÉRAS, Renata Meira; TRAVERSO-YÉPEZ, Martha. A. A maternidade na política de humanização dos cuidados ao bebê prematuro e/ou de baixo peso - Programa Canguru. Estudos Feministas, Florianópolis, v. 18, n. ${ }^{\circ}$ 1, p. 61-80, jan.-abr., 2010.

WILLIG, Carla. Introduction qualitative research in psychology: adventures in theory and method. Buchigham: Open University Press, 2010.

ZEICHNER, Ken. Repensando as conexões entre a formação na universidade e as experiências de campo na formação de professores em faculdades e universidades. Educação, Santa Maria, v. 35, n. ${ }^{\circ} 3$, p. 479-504, set.-dez. 2010.

* Mestre em Estudos Interdisciplinares sobre a Universidade - Instituto de Humanidades, Artes e Ciências pela Universidade Federal da Bahia, Salvador, Bahia, Brasil.

** Docente do Programa de Pós Graduação Estudos Interdisciplinares sobre a Universidade - Instituto de Humanidades, Artes e Ciências pela Universidade Federal da Bahia, Salvador, Bahia, Brasil.

\section{Correspondência}

Renata Meira Véras - Universidade Federal da Bahia, Instituto de Humanidades, Artes e Ciências Milton Santos. Avenida Ademar de Barros, s/n PAFIII - Ondina. CEP: 40170110. Salvador, Bahia, Brasil.

E-mail: sayurikuratani@gmail.com - renatameiraveras@gmail.com

Recebido em 31 de outubro de 2017

Aprovado em 28 de maio de 2018

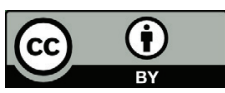

This work is licensed under a Creative Commons Attribution 4.0 International (CC BY 4.0). 
